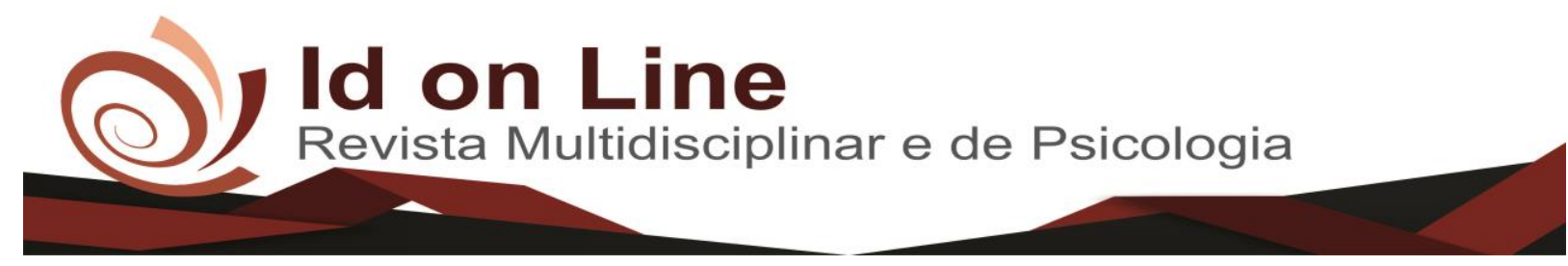

Artigo de Revisão

\title{
Caracterização dos Recém-Nascidos Internados em Unidades de Terapia Intensiva
}

\author{
Maria Cristina Nascimento de Freitas ${ }^{1}$; Andréia Oliveira Barros Sousa ${ }^{2}$; Symara Abrantes Albuquerque de Oliveira \\ Cabral $^{3}$; Maria Carmem Batista de Alencar ${ }^{4}$ :Maria do Socorro de Sousa Estrela Guedes ${ }^{5}$. Gislene Farias de Oliveira 6
}

\begin{abstract}
Resumo: Prestar cuidados ao ser humano hospitalizado requer muita competência e segurança e negligenciar essa assistência possibilita erros imensuráveis que acarreta danos indesejáveis, tanto ao paciente quanto para o profissional e o serviço de saúde. Por isso é de extrema relevância caracterizar a clientela assistida principalmente quando se trata de recém-nascidos de alto risco. Portanto, objetivou-se com este trabalho, de forma geral caracterizar os RNs internados em UTIs Neonatais, elencando os principais distúrbios responsáveis pelas internações dos RNs. Foi realizada uma busca ativa nas bases de dados eletrônicos MEDLINE/ PubMED e LILACS, e na SciELO.. A amostra foi constituída de 05 artigos científicos indexados nos bancos de dados de acesso livre: Sistema Online de Busca e Análise de Literatura Médica (MEDLINE) e Literatura Latino Americano e do Caribe em Ciências de Saúde (LILACS). A pesquisa foi desenvolvida nos meses de janeiro a março de 2016. Por essas considerações é necessário dentro dessas unidades conhecer o perfil sócio demográfico desses RNs assim como os principais distúrbios que os acometem pensando em estabelecer as melhores estratégias assistenciais buscando melhorar a qualidade dos cuidados prestados.
\end{abstract}

Descritores: Recém Nascidos; Enfermagem Neonatal; Unidade de Terapia Intensiva Neonatal.

\section{Characterization Newborn Hospitalized in Intensive Care Units}

Summary: Providing care for the hospitalized human requires a lot of competence and security and neglecting this assistance allows for immeasurable errors that lead to undesirable damages to both the patient and the professional and the health service. Therefore it is extremely important to characterize the assisted clientele mainly when it comes to high risk newborns. Therefore, the objective of this study was to characterize the infants hospitalized in Neonatal ICUs, listing the main disorders responsible for NB hospitalizations. An active search was performed in the electronic databases MEDLINE / PubMED and LILACS, and in SciELO. The sample consisted of 05 scientific articles indexed in the databases of free access: Online System of Search and Analysis of Medical Literature (MEDLINE) and Latin American and Caribbean Literature in Health Sciences (LILACS). The research was developed from January to March 2016. For these considerations it is necessary within these units to know the socio-demographic profile of these newborns as well as the main disturbances that affect them, thinking of establishing the best care strategies to improve the quality of the care that is provide.

Keywords: Newborn; Neonatal Nursing; Neonatal Intensive Care Unit.

\footnotetext{
${ }^{1}$ Enfermeira. Especialista em Enfermagem em neonatologia e pediatria. Especialista em Enfermagem em UTI, urgência e emergência.

${ }^{2}$ Enfermeira e Professora da UFCG. Especialista em Obstetrícia.

${ }^{3}$ Enfermeira, especialista em Obstetrícia. Mestre em Sistemas Agroindustriais e Doutoranda em Ciências da Saúde.

${ }_{5}^{4}$ Enfermeira, especialista em Saúde Pública, Mestre em Sistemas Agroindustriais.

${ }^{5}$ Graduação em Enfermagem pela Universidade Federal da Paraíba. Pós Graduada em Saúde da Família pela UFPB e Especialista em Enfermagem Obstétrica pela Faculdade Santa Maria. Atualmente é Enfermeira do Hospital Regional de Cajazeiras-PB na qualidade de Gerente da Maternidade Dr. Deodato Cartaxo / UCINco / UCINca e coordenadora da Sala do Coração - HRC.

${ }^{6}$ Doutorado em Psicologia Social pela universidade Federal da Paraíba - UFPB. Pós doutorado em Ciências da saúde pela FMABC-SP. Professora Associada da universidade Federal do cariri - UFCA. Contato: gislenefarias@ gmail.com.

228 Id on Line Rev. Mult. Psic. V.12, N. 40. 2018 - ISSN 1981-1179

Edição eletrônica em http://idonline.emnuvens.com.br/id
} 


\section{Considerações Iniciais}

Uma criança que nasce no pré-termo está muito mais susceptível as influências do meio extrauterino por não possuir ainda maturação fisiológica suficiente, o que poderá acarretar inúmeras complicações. Apesar do avanço tecnológico que possuímos atualmente e que a cada dia desponta com novos equipamentos e terapêuticas, o útero continua sendo ainda o local ideal para o desenvolvimento psico-bio-fisio-neuromotor do feto (concepto).

É considerada prematura, ou pré-termo, a criança com idade gestacional menor que 37 semanas. Long e Lucey classificaram os recém- nascidos (RN) segundo o peso e a idade gestacional colocando este limite em 38 semanas (RIBEIRO, 2005). Sendo assim, ao nascer, um recém-nascido prematuro (RNPT) ou com baixo peso, é levado para longe da mãe, para um tratamento intensivo que possibilite sua recuperação (BARBOSA, 2005). Então, quanto mais rápido for assistido por uma equipe capaz e eficaz, sua recepção tende a ser menos traumática e com uma boa probabilidade de êxito.

Portanto, a Unidade de Terapia Intensiva Neonatal (UTIn) é um ambiente para tratar o $\mathrm{RN}$ prematuro e os RNs que de alguma forma correm um risco de morte, ou ainda, que apresentam algum tipo de problema ao nascer (BUSKO; MURATA, 2008).

As Unidades de Terapia Intensiva (UTIs) são setores hospitalares destinados ao atendimento de pacientes graves ou de risco, que dispõem de assistência médica e de enfermagem ininterruptas, com equipamentos específicos próprios, recursos humanos especializados e que tem acesso a outras tecnologias destinadas a diagnóstico e terapêutica (BOWDEN; GREENBERG, 2005). A UTIn recebe pacientes de zero a vinte e oito dias. Tais pacientes possuem seu sistema imunológico ainda em processo de formação, o que torna o neonato mais susceptível a infecção hospitalar (BRASIL, 1994).

Os RNPT são seres humanos em uma época de sua existência que requerem cuidados intensos e atenção vigilante a todo momento. São representantes de um universo seleto, que por si só advém com suas particularidades ímpares, desta forma atraem a atenção dos profissionais de saúde, por apresentarem uma inabilidade em se adequarem à vida extrauterina.

Segundo a Organização Mundial de Saúde (OMS) (2006) parto pré-termo é aquele ocorrido antes de 37 semanas de gestação (259 dias) sendo recém-nascido de baixo-peso o bebê que nasce com peso inferior a 2.500g (COSTA; MARB, 2004). 
Segundo a OMS, no mundo nascem anualmente 20 milhões de bebês prematuros e com baixo peso, dos quais um terço morre antes de completar um ano de vida e em cada 10 recémnascido vivos, 09 tem peso inferior a 1.000g ao nascer. (BUSKO; MURATA, 2008)

A prematuridade, por si só, constitui-se em um grande problema na saúde pública, por tratar-se de determinante da morbimortalidade neonatal, principalmente em países subdesenvolvidos. Neste sentido, Kenner (2011) afirma que a imaturidade geral pode levar a disfunção em qualquer órgão ao sistema corporal. Sendo assim, o neonato prematuro corre o risco de sofrer uma ampla faixa de problemas, incluindo síndrome do desconforto respiratório, apneia, displasia bronco pulmonar, persistência do canal arterial, termorregulação ineficaz, hiperglicemia, hemorragia intraventricular, disfunção gastrintestinal, retinopatia, hiperbilirrubinemia e infecção.

Por essas considerações, faz-se necessário o conhecimento do perfil sócio demográfico desses RNs assim como os principais distúrbios que os acometem de modo a pensar em estabelecer as melhores estratégias assistenciais buscando melhorar a qualidade dos cuidados prestados.

O período neonatal abrange os primeiros vinte e oito dias de vida do neonato após o nascimento (DARÉ JÚNIOR, 2008). A Sociedade Brasileira de Pediatria corrobora com os autores e ainda refere ainda o termo recentemente-nascido considerando os primeiros minutos ou horas que se seguem ao nascimento. $\mathrm{O}$ termo bebê ou lactente inclui o período neonatal e se entende até 1 ano de idade (12 meses). A propósito, dessas diretrizes, o termo criança se aplica ao grupo de 1 a 8 anos de idade (DUARTE; ELLENSOHN, 2007).

Atualmente a OMS adota a classificação relacionada à idade gestacional do recém nascido $(\mathrm{RN})$ especificando que o pré-termo é aquele nascido com menos de 37 semanas de idade gestacional (ou com menos de 259 dias de gestação), a termo aquele nascido entre $37^{\mathrm{a}}$ e $41^{\text {a }}$ semanas e seis dias de idade gestacional, e pós-termo aqueles nascidos com 42 semanas ou mais de idade gestacional (TAMEZ; SILVA, 2008).

Lucena (2015) ainda registra a classificação dos prematuros. Segundo esse autor especificamente existem três grupos de RNs pré-termos: o limítrofe que inclui as crianças nascidas com Idade Gestacional (IG) entre 35 e 36 semanas, peso ao nascimento entre 2.200 e $2.800 \mathrm{~kg}$, com comprimento de 45 a $46 \mathrm{~cm}$ e perímetro cefálico medindo aproximadamente 32 a $33 \mathrm{~cm}$; a prematuridade moderada que inclui os nascidos com IG entre 3034 semanas, peso ao nascimento entre 1.600 e $2.300 \mathrm{~kg}$, com comprimento variando de 39 a $44 \mathrm{~cm}$ e perímetro 
cefálico de 29 a 32cm e por último a prematuridade extrema com IG inferior a 30 semanas, peso menor que $1.500 \mathrm{~kg}$, comprimento e perímetro cefálico menor que 28 e $29 \mathrm{~cm}$.

Esse mesmo autor ainda relata a classificação relacionada ao peso no momento do nascimento: Recém- Nascidos de Muito Baixo Peso (RNMBP) cujo peso é inferior a $1.500 \mathrm{~kg}$; Recém-Nascidos de Muitíssimo Baixo Peso (RNMMBP) com peso ao nascimento menor que $1.000 \mathrm{~kg}$.

Os RNs de alto risco são seres humanos em uma época de sua existência que requerem cuidados intensos e atenção vigilante a todo o momento. São representantes de um universo seleto, que por si só advém com suas particularidades ímpares, desta forma atraem a atenção dos profissionais de saúde, por apresentarem uma inabilidade em se adequarem à vida extrauterina.

Lucena (2015) afirma que o grupo de RNs, não é homogêneo, seu aspecto físico é diverso, conforme ele seja mais ou menos maduro, somando-se a isso uma gama de problemas funcionais de maneira variada, em função de sua maior ou menor IG.

Kenner (2011) ainda afirma que a imaturidade geral pode levar a disfunção em qualquer órgão ao sistema corporal. Sendo assim, o neonato de alto risco corre o risco de sofrer uma ampla faixa de problemas, incluindo síndrome do desconforto respiratório, apneia, displasia bronco pulmonar, persistência do canal arterial, termorregulação ineficaz, hiperglicemia, hemorragia intraventricular, disfunção gastrintestinal, retinopatia, hiperbilirrubinemia e infecção.

Portanto, os cuidados com esses bebês de alto risco consistem em uma constante luta da vida e da morte, por ser um grupo que encontra-se isolado do mundo linguístico além da inabilidade de adequação ao seu meio extra útero. Devido a isso, os seus cuidadores precisam estar sensíveis para entender, e muitas vezes interpretar, uma linguagem tão própria. Uma careta pode significar um pedido de socorro, de que o ritmo está acelerado, um olhar débil pode significar um alerta e /ou um não estou bem.

Hoje já se sabe que, devido a pouca distância que confere o corpo do pré-termo, a proximidade anátomo-fisiológica, mesmo com sua imaturidade, eles são capazes de sentir dor em grande intensidade, e como já dito são mais susceptível a fatores intrínsecos e extrínsecos ao seu meio (GUYTON; HALL, 2006). Tais fatores, associados a condições como a prematuridade e outras patologias apresentadas pelo bebê, podem contribuir para a elevação da incidência da morbimortalidade nessa faixa-etária (DUARTE; ELLENSOHN, 2007). 
Além disso, os recém-nascidos conforme descrevem Mussi-Pinhata; Rego (2005) possuem diversos fatores que facilitam a invasão bacteriana e a ocorrência de sepse neonatal. As barreiras mecânicas imaturas, as funções restritas de neutrófilos, as baixas concentrações plasmáticas de anticorpos específicos, as atividades diminuídas das proteínas do sistema complemento e a insuficiente cooperação entre linfócitos T e B predispõem esses bebês a uma invasão bacteriana.

Analisando, portanto essas reflexões para a realização desse estudo foi inicialmente elaborada a seguinte questão norteadora: Quais os distúrbios mais comuns responsáveis pela internação do neonato na UTIN?

Após a análise dos estudos mais relevantes elaborou-se como objetivo desse trabalho avaliar os distúrbios mais comuns responsáveis pela internação do neonato na UTIN.

\section{Considerações Metodológicas}

Trata-se de um estudo descritivo, exploratório, retrospectivo, utilizando o método quantitativo, com a utilização de artigos selecionados de periódicos da Biblioteca Virtual em Saúde (BVS). O levantamento das publicações foi realizado no período de fevereiro a março de 2017, nos bancos de dados de acesso livre: Sistema Online de Busca e Análise de Literatura Médica (MEDLINE) e Literatura Latino Americano e do Caribe em Ciências de Saúde (LILACS). Após a leitura de todos os artigos encontrados (309), foram selecionados 05 artigos científicos pertinentes à questão norteadora elencada e que atendiam aos critérios de inclusão previamente estabelecido pelas pesquisadoras.

Foram utilizados como critérios para a inclusão nesta pesquisa: artigos publicados com idioma português, que encontravam-se disponíveis nas bases em versão completa com livre acesso ao publico; artigos publicados, entre os anos de 2009 e 2015; publicações relacionadas aos descritores propostos. Os critérios utilizados para a exclusão foram: artigos não indexados nos bancos de dados: Medline e Lilacs; artigos repetidos nas duas base de dados; artigos publicados em idiomas que não o português; e artigos cuja temática não se adequasse aos objetivos propostos

A variável primária trata-se da identificação dos distúrbios relacionados a internação dos neonatos em Unidade de Terapia Intensiva Neonatal (UTIN). As variáveis secundárias são: 
incidência dos principais distúrbios neonatais encontrados na UTIN, aspectos epidemiológicos relacionados ao tempo de internação dos neonates, prematuridade e imaturidade neonatal como desencadeadores da internação e atraso do desenvolvimento do neonato relacionado a internação na UTIN.

Os cinco Descritores de Ciências da Saúde (DeCS) selecionados para a busca foram Recém Nascidos, Enfermagem Neonatal, Assistência de Enfermagem, Neonatologia e Unidade de Terapia Intensiva Neonatal. Esses termos foram consultados no banco de dados MEDLINE e LILACS em um primeiro momento de forma isolada, e depois em associação utilizando o operador lógico booleano AND.

Os dados foram coletados após inclusão de palavra chave na de pesquisa nas bases de dados, em seguida os artigos foram filtrados para obter os critérios de inclusão e exclusão da pesquisa.

Para a realização desse estudo foi inicialmente elaborada a seguinte questão norteadora: Quais os distúrbios mais comuns responsáveis pela internação do neonato na UTIN?

A leitura das informações foi realizada em caráter exploratório, objetivando selecionar as obras de interesse para a pesquisa. Após a leitura analítica dos textos selecionados, foram ordenadas as informações contidas nos referenciais teóricos sendo por fim realizada uma leitura de caráter interpretativo que relacionou as conclusões referidas pelos autores para o tema em questão.

Durante todas as etapas analíticas foram confeccionados fichamentos para uma melhor organização e compreensão aos resultados, sendo estes categorizados baseando-se no método de revisão integrativa.

\section{Resultados Estatísticos}

De acordo com os dados coletados, no quadro I têm-se uma explanação dos artigos encontrados para análise quanto o título do trabalho, área de conhecimento e o ano de publicação deste. Tendo sido, os artigos codificados de A1 a A5 em ordem crescente do ano de publicação. 
Quadro I. Caracterização dos artigos científicos elencados em relação aos autores, título, área de conhecimento e ano de publicação.

\begin{tabular}{|c|c|c|c|c|}
\hline $\begin{array}{l}\text { Código do } \\
\text { Artigo }\end{array}$ & Autores & Título & $\begin{array}{c}\text { Área de } \\
\text { Conhecimento }\end{array}$ & Ano \\
\hline A1 & LIMA, S.S.de et al & $\begin{array}{l}\text { Aspectos clínicos de } \\
\text { recém-nascidos } \\
\text { admitidos } \\
\text { Unidade de Terapia } \\
\text { Intensiva de hospital } \\
\text { de referência da } \\
\text { Região Norte do } \\
\text { Brasil }\end{array}$ & Ciências da Saude & 2015 \\
\hline A2 & $\begin{array}{c}\text { VASCONCELOS, E.M; } \\
\text { PEDROSA, A.K.; MARTINO, } \\
\text { M.V. DE. }\end{array}$ & $\begin{array}{l}\text { Perfil de internação de } \\
\text { recém-nascidos de } \\
\text { alto risco em uma } \\
\text { UCI neonatal }\end{array}$ & Enfermagem & 2013 \\
\hline A3 & ARRUÉ, A.M. et al & $\begin{array}{l}\text { Caracterização da } \\
\text { morbimortalidade de } \\
\text { recém-nascidos } \\
\text { internados em UTI } \\
\text { neonatal }\end{array}$ & Enfermagem & 2013 \\
\hline A4 & $\begin{array}{l}\text { MUCHA, F; FRANCO, S.C; } \\
\text { SILVA, G.A.G. }\end{array}$ & $\begin{array}{lr}\text { Frequência } & \mathrm{e} \\
\text { características } & \\
\text { maternas e do recém } \\
\text { nascido associadas à } \\
\text { internação } & \text { de } \\
\text { neonatos em UTI no } \\
\text { município } & \text { de } \\
\text { Joinville, } & \\
\text { Santa Catarina - } & \\
2012 & \end{array}$ & Enfermagem & 2013 \\
\hline A5 & GRANZOTTO, J.A. et al & $\begin{array}{l}\text { Análise do perfil } \\
\text { epidemiológico das } \\
\text { internações em uma } \\
\text { unidade de terapia } \\
\text { intensiva neonatal }\end{array}$ & Medicina & 2012 \\
\hline
\end{tabular}

Fonte: Base de dados MEDLINE, BDENF E LILACS, 2016.

Analisando o Quadro I, observa-se que 04 artigos foram publicados em periódicos que tem como área de conhecimento a Enfermagem. Isso reforça a busca de uma prática profissional baseada em evidências científicas destacando essa profissão como ciência em expansão. 
A Enfermagem possui como fundamento norteador uma prática assistencial voltada a evidência científica, e por isso observa-se um aumento da quantidade de pesquisas elaboradas nessa área. Bub; Liss (2006) entendem a enfermagem como ciência, arte e tecnologia responsáveis por suprir as necessidades do ser humano. Como ciência ela será responsável por determinar conhecimentos novos para o uso prático, elaborando técnicas que possam resolver problemas cotidianos de forma usual satisfazendo necessidades, gerando bem estar, aperfeiçoando competências e promovendo a vida.

Diversas pesquisas vêm sendo realizadas com o propósito de melhorar a assistência prestada pela equipe de enfermagem. É necessário constantemente modificar conceitos a fim de se atingir a qualidade nas atividades desenvolvidas. Em relação aos objetivos de estudo de cada artigo, denota-se uma variação significativa entre a temática em diferentes perspectivas, sendo destacada a preocupação quanto às ocorrências de eventos adversos em hospitais referente a erros de medicação e a relevância dos prontuários para colher as informações.

Quadro II. Caracterização dos Artigos Científicos elencados em relação ao periódico, Capesqualis e objetivos propostos.

\begin{tabular}{|c|c|c|l|}
\hline $\begin{array}{c}\text { Código do } \\
\text { Artigo }\end{array}$ & Periódicos & $\begin{array}{c}\text { CAPES- } \\
\text { Qualis }\end{array}$ & \multicolumn{1}{c|}{ Objetivos Propostos } \\
\hline A1 & $\begin{array}{c}\text { Arquivos } \\
\text { Brasileiros de } \\
\text { Ciências da Saúde }\end{array}$ & B4 & $\begin{array}{l}\text { Descrever as características clínicas dos recém- } \\
\text { nascidos admitidos em uma Unidade de Terapia } \\
\text { Intensiva Neonatal de um hospital público de } \\
\text { referência em atenção materno infantil da região norte, } \\
\text { no ano de 2013 }\end{array}$ \\
\hline A2 & Rev enferm UFPE & B2 & \begin{tabular}{l} 
Traçar o perfil dos neonatos de alto-risco \\
\hline A3
\end{tabular} \\
Rev Enferm UFSM & B3 & $\begin{array}{l}\text { Caracterizar a morbimortalidade dos recém-nascidos } \\
\text { (RN) internados } \\
\text { em uma Unidade de Terapia Intensiva Neonatal do sul } \\
\text { do Brasil }\end{array}$ \\
\hline A4 & $\begin{array}{c}\text { Rev. Bras. Saúde } \\
\text { Matern. Infant }\end{array}$ & B3 & $\begin{array}{l}\text { Determinar a frequência e os fatores } \\
\text { associados à internação de recém-nascidos em UTI } \\
\text { neonatal no município de Joinville, Santa Catarina. }\end{array}$ \\
\hline A5 & $\begin{array}{c}\text { Revista da } \\
\text { AMRIGS }\end{array}$ & B4 & $\begin{array}{l}\text { Conhecer as características da população e os fatores } \\
\text { relacionados com a internação na Unidade de } \\
\text { Tratamento Intensivo Neonat do Hospital Escola da } \\
\text { UFPel entre os anos 2008 e 2010. }\end{array}$ \\
\hline
\end{tabular}

Fonte: Base de dados MEDLINE, BDENF E LILACS, 2016. 
Todos os periódicos relacionados seguiram como critério para uma estratificação da qualidade da produção intelectual elencada, o processo de qualificação Qualis. Foram incluídos publicações que se enquadravam entre Capes Qualis B2 e B4.

Segundo esse critério os periódicos classificados como B possuem excelência nacional, validando a confiabilidade dos artigos, conforme denota a própria CAPES. Esse critério de estratificação de qualidade possui grande notoriedade para o campo científico, pois estabelece regularmente a qualidade dos periódicos garantindo aos pesquisadores uma certificação qualificada dessa publicação.

Em relação aos objetivos de estudo de cada artigo observa-se que a temática foi abordada com ênfase não só nas características dos RNs, mas também nos principais fatores relacionados com a internação na UTIN.

Quadro III. Caracterização dos principais fatores associados a internação dos RNs

\begin{tabular}{|c|c|c|}
\hline Fatores associados a internação & $\mathbf{N}^{\mathbf{0}}$ de artigos & $\mathbf{\%}$ \\
\hline Prematuridade & 05 & 100 \\
\hline Baixo peso ao nascer & 04 & 80 \\
\hline Infecção Neonatal & 04 & 80 \\
\hline Distúrbios Respiratórios & 04 & 80 \\
\hline Anóxia Perinatal & 03 & 60 \\
\hline Malformações congênitas & 01 & 20 \\
\hline
\end{tabular}

Fonte: Base de dados MEDLINE, BDENF E LILACS, 2016.

Analisando o Quadro III observa-se que a prematuridade destacou-se como fator predominante para a internação dos RNs, acompanhado do baixo peso ao nascer, das infecções neonatais e distúrbios respiratórios.

Verificou-se que quanto maior o número de complicações que agravam o estado de saúde do bebê, maior é o tempo que este bebê permanece internado na unidade de cuidados neonatais, menor é o contato com os cuidadores e, principalmente a mãe, favorecendo ao maior risco de mortalidade e morbidade.

Quanto ao tempo de interação, importante considerar os dados do gráfico 1. 
Gráfico 1: Tempo de internação de neonatos em Unidades de Terapia Intensiva.

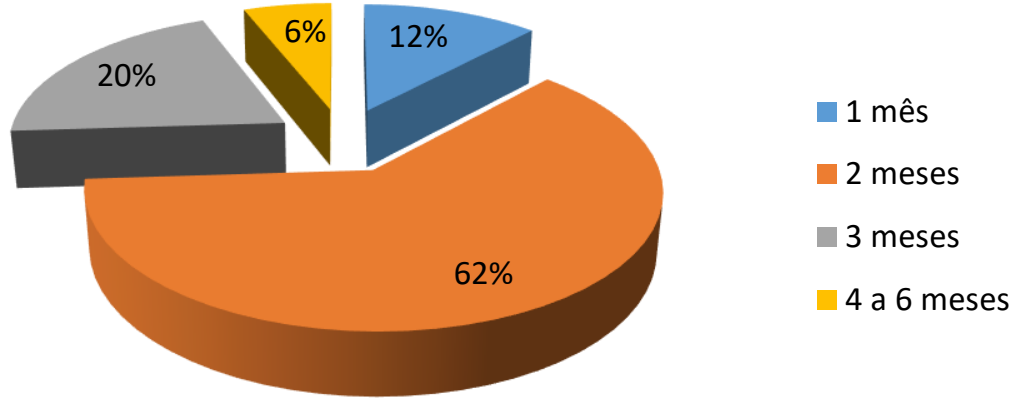

Fonte: Base de dados MEDLINE, BDENF E LILACS, 2016.

No gráfico 1 observa-se que nos estudos encontra-se descrito o tempo médio de internação desses usuários dentro das UTINs. 82\% desses RNs permanecem entre 2 e 3 meses dentro dessas unidades o que aumenta as chances de complicações e surgimento de comorbidades aos mesmos.

O gráfico 2 traz a abordagem da idade gestacional no momento da internação na UTI.

Gráfico 2: Idade Gestacional no momento da internação na Unidade de Terapia Intensiva.

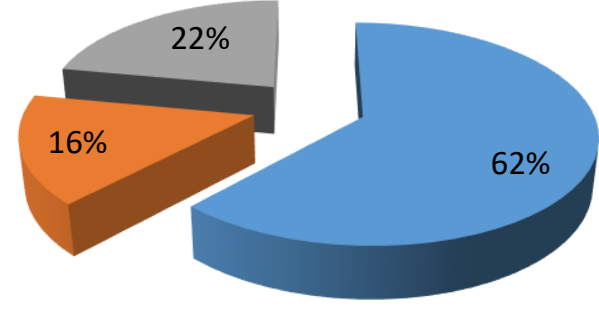

- Prematuro

Normotermo

Pós-maturo

Fonte: Base de dados MEDLINE, BDENF E LILACS, 2016. 
É possível observar no gráfico 2 a maior incidência de internações dos recém nascidos prematuros dentro das UTINs. Todos os autores relatam esse dado estatístico em suas pesquisas e reinteram essa condição como agravante para necessidade de cuidados intensivos.

\section{Análise Discursiva}

Quando se fala em publicações científicas encontra-se uma série de tipos de trabalhos, metodologias utilizadas e meios de divulgação de resultados. A análise destes pontos dá uma ideia de quão confiável é o estudo, tendo em vista que, por exemplo, os artigos científicos apresentam melhor seleção dos resultados levantados após um estudo sendo assim melhores fontes de conhecimento científico, além de serem mais atuais que os conhecimentos apresentados nos livros.

Com relação à área de estudo dos autores das pesquisas prevaleceram a área de enfermagem e a médica. Ambas as profissões apresentam especializações na área de saúde pediátrica e neonatal o que contribui para a busca de estratégias que minimizem a internação dentro das UTIs neonatais.

Sabendo que a hospitalização constitui-se em um elemento de risco pelas condições biológicas em que o bebê se encontra e pelo contexto do ambiente que se apresenta (MOTA, 2005).

Lima, et al (2010), Arrue, et al (2007), e Granzotto et al (2012) observaram em relação ao desenvolvimento neuropsicomotor que quanto maior o tempo que o lactente permaneceu internado, menor foi seu desempenho. Os bebês que necessitaram de hospitalização por mais de 30 dias, devido a investigação de diagnóstico ou alguma morbidade, tiveram risco sete vezes maior de apresentar suspeita de atraso, demonstrando uma correlação negativa, de moderada a forte, entre tempo de internação e desenvolvimento.

Giachetta et al (2010) utilizando a Escala Motora Infantil de Alberta (EMIA), avaliaram a correlação entre o tempo de internação na UTI neonatal e o desenvolvimento motor de recémnascidos. O grupo de bebês que permaneceu mais tempo internado, média de 50 dias, apresentou escores mais baixos, apontando maior comprometimento motor, enquanto o grupo que permaneceu menos tempo, média de 20 dias, apresentou escores compatíveis com o desenvolvimento adequado para a idade. 
Além das complicações neonatais atualmente apontadas como fatores de risco para o comprometimento do desenvolvimento neurológico e intelectual normal, o impacto do ambiente hospitalar e o tempo em que os RNPT permanecem internados exercem papel importante no desenvolvimento neuropsicomotor (VASCONCELOS; PEDROSA; MARTINO, 2013; MUCHA; FRANCO; SILVA, 2015).

Alguns estudos mostram que a internação em UTIN deve ser considerada como um dos possíveis fatores de risco para o atraso no desenvolvimento (LIMA, et al., 2015; GRANZOTTO, et al., 2012; GIANCHETTA, et al., 2010).

Tomando por base os principais fatores contribuintes para a internação na UTI Neonatal, de acordo com os artigos pesquisados observou-se que a prematuridade, baixo peso, infecção neonatal, distúrbios respiratórios, anóxia perinatal e as malformações congênitas foram as principais causas para a internação na UTI neonatal.

Vasconcelos, Pedrosa e Martino (2013) destacam que a imaturidade sistêmica encontrada nos RNs pré-termos constitui um grande problema na saúde pública, por tratar-se de determinantes da morbimortalidade neonatal, principalmente em países subdesenvolvidos.

O RNPT dependendo de sua maturidade ao nascimento e do tipo e da intensidade dos fatores que atuaram durante sua vida intrauterina, poderá apresentar um maior risco de distúrbios durante o período neonatal. Em geral os recém nascidos pré-termos moderados e extremos têm uma possibilidade maior de desenvolver problemas respiratórios e consequentemente asfixia perinatal, o que aumenta as chances de mortalidade (MUCHA; FRANCO; SILVA, 2015; BARBOSA, 2015).

Uma criança que nasce pré-terma está muito mais susceptível as influências do meio extrauterino por não possuir ainda maturação fisiológica suficiente, o que poderá acarretar inúmeras complicações (KNOBEL, 2005).

Apesar do avanço tecnológico que possuímos atualmente e que a cada dia desponta com novos equipamentos e terapêuticas, o útero continua sendo ainda o local ideal para o desenvolvimento psico-bio-fisio-neuromotor do feto (concepto) (GRANZOTTO, et al., 2012; GRANZOTTO, et al., 2012; VASCONCELOS; PEDROSA; MARTINO, 2013; MUCHA; FRANCO; SILVA, 2015). 


\section{Considerações Finais}

Os neonatos que necessitam de internação hospitalar, após o nascimento, se apresentam muito vulneráveis e requerem uma assistência além da estabilidade hemodinâmica, necessitam de cuidados integrais, de qualidade de vida intra e extra hospitalar. Pensando nisso, têm-se aumentado os questionamentos sobre os fatores de risco hospitalares que, além de atuarem diminuindo o padrão de saúde presente, trazem efeitos deletérios futuros. Assim, muitos profissionais de saúde estão investigando, pesquisando, repensando suas práticas e adequandoas de acordo com a necessidade da clientela, buscando garantir não só o restabelecimento da saúde dentro do ambiente hospitalar, mas sim após a alta, podendo-se afirmar que, a busca pelo conhecimento contribui para uma visão mais crítica e consciente do recém-nascido e de sua família, enfatizando a visão holística do RN.

Quando se pensa nos cuidados prestados aos neonatos, na vida iniciada e em constante crescimento e formação, a assistência deve atravessar as paredes hospitalares, se tornando em longo prazo. A equipe de enfermagem que atua na UTIN encontra-se em uma busca constante pela qualidade dos cuidados prestados ao recém-nascido. Se os cuidadores em enfermagem conhecerem as necessidades do neonato e o risco a que está exposto durante a internação na UTI neonatal, podem vir a proporcionar condições para que sua permanência seja menos traumática possível para que não venha afetar seu desenvolvimento físico, mental e social.

Vale ressaltar que a hospitalização infantil e seus efeitos negativos repercutem não somente na vida do bebê, mas altera toda a dinâmica familiar, gerando sentimentos diversos resultantes da perda de controle no funcionamento da família, das inseguranças quanto à capacidade de retomar o equilíbrio e das dúvidas relacionadas à situação vivenciada.

A melhora na sobrevida destes bebês impõe um desafio aos profissionais de saúde: devolver às famílias e à sociedade uma criança capaz de desenvolver de maneira plena o seu potencial afetivo, cognitivo e produtivo.

\section{Referências}

ARRUE, A.M. ; NEVES, E.T.; SILVEIRA, A. da; PIESZAK, G.M. Caracterização da morbimortalidade de recém-nascidos internados em UTI neonatal. REUFSM. v.3. n.1. 2013. 
BARBOSA, A.R.F. Consequências da prematuridade no sistema respiratório. Fac. de Med. Univ. Coimbra. Dissertação de mestrado. Março de 2015.

BARBOSA, A.R.F. Consequências da prematuridade no sistema respiratório. Fac. de Med. Univ. Coimbra. Dissertação de mestrado. Março de 2015.

BARROS, A.J.P.; LEHFELD, N.A.S. Projeto de Pesquisa: propostas metodológicas. 19 ed. Petrópolis, RJ: Vozes, 2010.

BOWDEN, V. R. GREENBERG, C. S. Cuidados de desenvolvimento do neonato: procedimentos de enfermagem pediátrica. Rio de Janeiro: Guanabara Koogan, 2005.

BRASIL. Manual de assistência ao recém nascido. Brasília: Ministério da saúde, 1994.

BUB, M.B.C.; LISS, P.E. Metodologias do cuidado de enfermagem. In: KALINOWSKI, C.E. PROENF: Programas de Atualização em Enfermagem Saúde do Adulto. Ciclo 1. módulo 2. Porto Alegre: Artmed, 2006.

BUSKO M.; MURATA P. Neonates in intensive care endure painful procedures,mostly without analgesia. 2008. Disponível em <file://I:Leonates in intensive care endure painful procedures.without analgesia.htm>.

CAPES. Plataforma Sucupira. Disponível em: https://sucupira.capes.gov.br/sucupira/public/ lancamento/sobre.jsf. Acesso em 14 de março de 2016.

COSTA, H. P. F.; MARBA, S. T. Humanização e abordagem desenvolvimentista nos cuidados ao recém-nascido de muito baixo peso: o recém -nascido muito baixo peso. São Paulo: Atheneu, 2004.

DARÉ JÚNIOR, S. et al. Humanização e abordagem desenvolvimentista nos cuidados ao recémnascido de muito baixo peso: o recém -nascido muito baixo peso. São Paulo: Atheneu, 2014.

DUARTE, A. P. P.; ELLENSOHN, L. A operacionalização do processo de enfermagem em terapia intensiva neonatal. Rev. Enferm. UERJ. Rio de Janeiro. v. 15. n.4. out./dez. 2007.

GIACHETTA, L.; NICOLAU, C.M.; COSTA, A.P.B.M.; ZUANA, A.D. Influência do tempo de hospitalização sobre o desenvolvimento neuromotor de recém-nascidos pré-

termo. Fisioterapia e Pesquisa, São Paulo, v.17, n.1, p.24-9, 2010.

GRANZOTTO, J.A.; MOTA, D.M.; REAL, R.F.; DIAS, C.M.; TEIXEIRA, R.F.; MENTA FILHO, J.C. et al. Análise do perfil epidemiológico das internações em uma unidade de terapia intensiva neonatal. AMRIGS. v.56. n.4. Porto Alegre, 2012.

GUYTON, A. C.; HALL, J. E. Tratado de fisiologia médica. 11. ed. Rio de Janeiro: Elsevier, 2006.

KENNER, C. Enfermagem neonatal. Rio de Janeiro: Reichmann e Affonso, 2011.

KNOBEL, E. Terapia intensiva: pediatria neonatal. São Paulo: Atheneu, 2005. 
LIMA, S.S.de; SILVA, S.M.da; AVILA, P.E.S.; NICOLAU, M.V.; NEVES, P.F.M. das. Aspectos clínicos de recém-nascidos admitidos em Unidade de Terapia Intensiva de hospital de referência da Região Norte do Brasil. ABCS Health Sciences. v.40. n.2. 2015.

LIRA, M. M. F. L. Atendimento humanizado em unidade de terapia intensiva neonatal. Assistência ao recém-nascido de risco. 2004. Disponível em: <http://www.paulomargotto. com.br/documentos/12.doc>.

LUCENA, W. B. Sujeitos de uma realidade: características de bebês internados em UTI's Neonatais. [S.1]: UEPB, 2015.

MARCONDES, E. et al. Pediatria básica. 9. ed. São Paulo: Sarvier, 2003. v. 3.

MOTA, L. A. et al. Estudo comparativo do desenvolvimento sensório-motor de recém-nascido prematuros da unidade de terapia intensiva neonatal e método canguru. Revista Brasileira em Promoção da Saúde. v.18, n.4, 2005.

MUCHA, F.; FRANCO, S.C.; SILVA, G.A.G. Frequência e características maternas e do recém nascido associadas à internação de neonatos em UTI no município de Joinville, Santa Catarina - 2012. Rev. Bras. Saude Mater. Infant., v.15. n.2. Recife 2015.

MUSSI-PINHATA, M. M.; REGO, M. A.C. Particularidades imunológicas do pré-termo extremo: um desafio para a prevenção da sepse hospitalar. J.Pediatr. Porto Alegre, v.81,n.1, 2005.

REGO, J. D. PAIVA, I. S. Fisiologia da asfixia: reanimação neonatal. São Paulo: Atheneu, 2014.

RIBEIRO, M.A.C. Aspectos que influenciam a termorregulação: assistência de enfermagem ao recém-nascido pré-termo. 2005. Disponível em: <http://www.paulomargotto.com.br/ documentos/Termorregulação.doc.

SÁ, A.C.; FUGITA, R.M.I. A criatividade como Instrumento Básico em Enfermagem. In: CIANCIARULLO, T.I. (org.). Instrumentos Básicos para o cuidar: um desafio para a qualidade de assistência. São Paulo: Atheneu, 2005.

SEVERINO, A.J. Metodologia do trabalho científico. 23 ed. rev. e atualizada - São Paulo: Cortez, 2007.

TAMEZ, R. N. SILVA, M. J. P. Enfermagem na UTI neonatal: assistência ao recém nascido de alto risco. 3. ed. Rio de Janeiro: Guanabara Koogan, 2009.

VASCONCELOS, E.M.; PEDROSA, A.K.; MARTINO, M.F. de; Perfil de internação de recémnascidos de alto risco em uma UCI neonatal. Rev. Enf. UFPE. v.7. n.11. Recife 2013.

\section{Como citar este artigo (Formato ABNT):}

FREITAS, Maria Cristina N de; SOUSA, Andréia O. B.; CABRAL, Symara A. A. de O.; ALENCAR, maria Carmem, B de; GUEDES, Maria do Socorro de S. E.; OLIVEIRA, Gislene F. de. Caracterização dos RecémNascidos Internados em Unidades de Terapia Intensiva . Id on Line Rev.Mult. Psic., 2018, vol.12, n.40, p.228-242. ISSN: 1981-1179.

Recebido: $12 / 03 / 2018$

Aceito 14/03/2018 